\title{
E-Counselling: The Intention, Motivation and Deterrent among School Counsellors
}

\author{
Lai Wei Foon, Zaida Nor Zainudin*, Yusni Mohamad Yusop, Wan Norhayati Wan Othman \\ Faculty of Educational Studies, Universiti Putra Malaysia, Serdang, Malaysia
}

Received October 27, 2019; Revised December 30, 2019; Accepted January 15, 2020

Copyright $\odot 2020$ by authors, all rights reserved. Authors agree that this article remains permanently open access under the terms of the Creative Commons Attribution License 4.0 International License

\begin{abstract}
Internet technologies are rapidly changing our lives, so school counsellors are now facing challenges to provide innovative ways in order to support students in their preferred communication mode. This study sought to understand the perception of school counsellors towards $e$-counselling on (1) their intention to use e-counselling; (2) the motivators for them to offer $e$-counselling; and (3) the deterrent factors from offering $e$-counselling. 66 school counsellors completed this online survey. All had online communication experience with their students. Counsellors showed positive intention to apply $e$-counselling in schools only when $e$-counselling facilities were provided. Lack of competence in technical skill seemed to outweigh their intention to use $e$-counselling. Appropriate professional development, technical training and the practice-based research in school comparing effectiveness of $e$-counselling and face-to-face were the leading three motivators for school counsellors to use e-counselling. Fear of miscommunication due to unfamiliar online language, lack of professional development and technical skill training, lacks of technical resources were the key deterrents that deter their intention to offer to $e$-counselling The major contribution from this study indicated that school counsellors were receptive to offer e-counselling in school with the conditions that they were given adequate and appropriate professional development, technical trainings and e-counselling facilities.
\end{abstract}

Keywords Perceptions, School Counsellors, E-Counselling

\section{Introduction}

Internet technologies are rapidly changing our lives especially the pattern of how we communicate with one other. It has become a major part of the lives of some young people who spent a large amount of time using social media to communicate with friends and family (Mesch, 2012; Campbell \& Colmar, 2014). In Malaysia, those aged below 20 years old spent 6.7 hours daily online (Malaysia Communication Multimedia Commission, 2018), which is more than one quarter of their time online chatting, gaming, shopping and sourcing for information (National Health and Morbidity Survey 'NHMS', 2017).

With this phenomenon, school counsellors are now facing challenges to provide innovative ways in order to support students in their preferred communication mode. It is necessary for school counsellors to incorporate technology such as $e$-counselling into their counselling modalities so as to maximize the effectiveness of their role especially with the high penetration of Internet usage among students (Kok, 2016, Cipolletta, \& Mocellin, 2017).

$E$-counseling is also known as online counselling, cyber-therapy, and e-therapy (Richards \& Viganó, 2013), is defined as delivery of therapeutic interventions where communication between a trained professional counsellor and client are through online technologies at two different locations, without meeting face-to-face. (Richard \& Viganó, 2012; Zainudin \& Yusop, 2018). Traditionally, counselling relationship in school is through face-to-face communications pattern (Wilczenski, \& Coomey, 2006; Teh, Acosta, Hechanova, Garabiles, \& Alianan Jr, 2014). With the robust of Internet, $e$-counselling is expected to grow.

School counsellors were receptive towards e-counselling as an additional method of counselling (Glasheen et al., 2013; Kok, 2015; Teh et al., 2014), especially when their time in schools was stretched and the demand for counselling from students was increasing (Kit, Teo, Tan \& Park, 2017; Teh et al., 2014). The benefits of $e$-counselling practice allowed school counsellors handle students' issue at their convenient as there are no time restriction, space and distance concerns (Paterson, Laajala, \& Lehtelä, 2017). Moreover, accessibility is made easy nowadays as long as there is Internet access for counsellors and clients 
(Zainudin \& Yusop, 2018).

The disinhibition effect in $e$-counselling helps clients to eliminate their counselling stigmatizing problems, thus more receptive to counselling (Bambling, King, Reid \& Wegner, 2008; Cook \& Doyle, 2002; Gatti et al., 2016; Suler, 2004). Clients felt less intimidated and safer to discuss without the presence of counsellors (Mishna, Bogo \& Sawyer, 2012, Beidoğlu, Dinçyürek, \& Akıntuğ, 2015; Glasheen, Campbell and Shochet, 2015).

However, another school argued that the optimism to practice $e$-counselling may not have much evidence of effectiveness (Cook \& Doyle 2002; Zamani, Nasir \& Yusoof, 2010). The skepticism was mainly on the absence of body language or non-verbal cues that resulted in the missing elements of genuine and empathy which are vital in counselling session (Bambling et al., 2008; Sobella, Poynton \& Isaac, 2010; Beidoğluet al., 2015).

Furthermore, school counsellors expressed their concerns on lack of confidence in technological knowledge and skills (Steele, Jacokes \& Stone, 2014; Fang, Tarshis, McInroy \& Mishna, 2017). School counsellors found that keeping up with technical knowledge on learning new software, operational procedures and managing administrative issues posed challenges to them (Fang et al., 2017; Glasheen et al., 2013).

The perception towards $e$-counselling was often affected negatively when there is inadequate training and professional development. School counsellors felt less competence in their skill without constant update on the latest in online world and emerging online problems (Anthony, 2015). Besides, these trainings have to be appropriate and on-going as the online culture is dynamic and fast evolving (2015).

Additionally, barrier in online language between school counsellors and students become an obstacle for school counsellors to practise $e$-counselling (Haberstroh, 2010, Harrad \& Banks, 2016). The fear of miscommunication, misunderstanding and misinterpreting all the abbreviated texts and emoticons used is a valid worry among school counsellors (Callahan \& Inckle, 2012). This is because counselling relationship would easily affect, if not jeopardized, with misunderstanding of communication (Bambling et al., 2008).

There seemed to be a broken connection between the required services with the current upsurge information technology trend. Therefore, school counsellors should adjust and adopt this advanced tool in order to meet the needs of $e$-counselling (Gatti, Brivio \& Calciano, 2016; Kok, 2016; Zainudin \& Yusop, 2018).

Despite the increasing demand on $e$-counselling services by students, research on the perception of school counsellors towards $e$-counselling was limited. This study aimed to understand the perception of school counsellors towards $e$-counselling in Malaysia on (1) their intention to use e-counselling; (2) the motivators for them to offer $e$-counselling; and (3) the deterrent factors from offering $e$-counselling

\section{Objectives}

The objective of this study is to identify factors that affect the perceptions of school counsellors in adopting $e$-counselling, and to identify what are the possible motivators for offering the service and barriers that inhibit their use. This study sought to understand the perception of school counsellors towards $e$-counselling on (1) their intention to use e-counselling; (2) the motivators for them to offer $e$-counselling; and (3) the deterrent factors from offering $e$-counselling.

\section{Methodology}

The research study incorporated a descriptive survey design with school counsellors in one of the district in Selangor, Malaysia. The questionnaires contained total of seven demographic questions and 34 items measured by 5-point Likert type scale.

The questionnaire was divided into four sections as follows: demographic information, counsellors' intention to use e-counselling (Glasheen, Campbell \& Shochet, 2013), motivators for school counsellors to use e-counselling (Hennigan \& Goss, 2016), and factors that deter counsellors from using online counselling (Hennigan \& Goss, 2016). Permissions had been granted from authors for the use of instruments.

Besides descriptive analysis, Pearson correlation coefficient was used to see the relationships between the various categorical dependent variables. Demographic variables included gender, age, level of education, years of experience, status of counsellors' registration, type of schools in and experience of online technology with students, were used to identify the relationship against the categorical variable.

\section{Results}

\section{Demographic characteristics of school counsellors}

A total of 66 school counsellors responded to this survey. The demographic details that collected entailed gender, age range, highest level of education, years of experience as school counsellor, status of counsellor's registration, type of government schools (primary, secondary, national type and religion schools) and experiences of using online technology with students. Respondents were predominantly female at $83 \%(n=55)$ and $17 \%(n=11)$ were male. The ratio for this study has a slightly higher female 
dominated response. This skew mirrored to the gender distribution of teaching profession in Malaysia, which has a ratio of 70:30 for female and male (Malaysia Education Statistics' Quick Fact 2018).

$59 \%(n=39)$ was from age range of 30 to 39 years. Both 40 to 49 years, and 50 years old and above recorded $17 \%$ $(n=11)$ respectively. $74 \%(n=49)$ was degree holder with $60 \%(n=40)$ has more than 10 year experience. $55 \%(n=36)$ of total respondents were registered counsellors. It was very encouraging to know that $95 \%(n=61)$ of respondents had either email or chat or both usage experiences with students.

\section{Counsellors' intention to use $\boldsymbol{e}$-counselling}

For section three on 'Counsellors' intention to use $e$-counselling' (see Table 1), 65\% (n=43) indicated a positive intention to use e-counselling when facilities were made available in school; $54 \%(n=36)$ believed it was an effective counselling tools and only $51 \%(n=34)$ would be confident with a secure chat room to counsel. Only $45 \%$ $(n=30)$, less than half has confidence in their technical skill to provide $e$-counselling services. Overall the standard deviations were close to normal distribution.

\section{Main motivators to work therapeutically online with students}

Section two on "Main motivators to work therapeutically online with students (see Table 2), showed an average of $77 \%(n=51)$ respondents giving positive statements for each item, except question on 'Financial reward' that was less agreeable at $41 \%(\mathrm{n}=27)$. This statement was less applicable in Malaysia school context.

The leading motivators for school counsellors to use e-counseling were $91 \%(n=60)$ in favour of availability of technical equipment; $80 \%(n=53)$ showed positive attitude toward practice based research that was comparing e-counseling and face-to-face help; $79 \%(n=52)$ would practice if there were evidence of reaching students that may have psychological barriers easier compared to accessing face-to-face help and demand from students that $e$-counselling would make accessing the service easier.

Similar to section three, no significant correlation was found within the all the demographic variables against the summed single scale score of section four.

Table 1. Section 3 - Counsellors' intention to use e-counselling

\begin{tabular}{|c|c|c|c|c|c|c|c|c|}
\hline \multirow{2}{*}{ Item } & \multicolumn{2}{|c|}{ SA or A } & \multicolumn{2}{|c|}{$\mathrm{SD}$ or $\mathrm{D}$} & \multicolumn{2}{|c|}{ NE } & \multirow[b]{2}{*}{ M } & \multirow[b]{2}{*}{ SD } \\
\hline & $\%$ & $n$ & $\%$ & $n$ & $\%$ & $n$ & & \\
\hline $\begin{array}{l}\text { If e-counseling facilities were available in my school I would } \\
\text { use them }\end{array}$ & 65.1 & 43 & 15.2 & 10 & 18.6 & 12 & 3.64 & 1.01 \\
\hline E-counselling would be an effective way to counsel students. & 54.5 & 36 & 18.2 & 12 & 27.7 & 18 & 3.49 & 0.95 \\
\hline $\begin{array}{l}\text { I would be confident that a secure chat room would be a } \\
\text { suitable place to counsel students. }\end{array}$ & 51.5 & 34 & 28.8 & 19 & 20.0 & 13 & 2.91 & 1.09 \\
\hline $\begin{array}{l}\text { I have the required technical skills to provide e-counseling in } \\
\text { my school. }\end{array}$ & 45.5 & 30 & 36.4 & 24 & 21.2 & 14 & 2.95 & 1.01 \\
\hline
\end{tabular}

Note: $\mathrm{SA}=$ Strongly Agree; A=Agree; NE=Neither; D=Disagree; $\mathrm{SD}=$ Strongly Disagree. Percentage may not total 100 due to rounding

Table 2. Section 4 - Main motivators for school counsellors to work therapeutically online with students

\begin{tabular}{|c|c|c|c|c|c|c|c|c|}
\hline \multirow[b]{2}{*}{ Item } & \multicolumn{2}{|c|}{ SA or A } & \multicolumn{2}{|c|}{$\mathrm{D}$ or $\mathrm{SD}$} & \multicolumn{2}{|c|}{$\mathrm{NE}$} & \multirow[b]{2}{*}{ M } & \multirow[b]{2}{*}{ SD } \\
\hline & $\%$ & $n$ & $\%$ & $n$ & $\%$ & $N$ & & \\
\hline $\begin{array}{l}\text { Availability of e-counseling training for school } \\
\text { counsellors. }\end{array}$ & 87.8 & 58 & 3.0 & 2 & 7.5 & 5 & 4.27 & 0.67 \\
\hline Financial Reward. & 40.9 & 27 & 18.2 & 12 & 40.9 & 27 & 3.37 & 1.05 \\
\hline Availability of technical equipment and support. & 90.9 & 60 & 7.6 & 5 & 1.5 & 1 & 4.43 & 0.71 \\
\hline $\begin{array}{l}\text { Evidence of reaching students that may have psychological } \\
\text { barriers to accessing face-to-face help }\end{array}$ & 78.8 & 52 & 3.0 & 2 & 18.2 & 12 & 4.11 & 0.87 \\
\hline $\begin{array}{l}\text { Practice based research in schools comparing online with } \\
\text { face-to-face working. }\end{array}$ & 80.3 & 53 & 1.5 & 1 & 18.2 & 12 & 4.18 & 0.79 \\
\hline $\begin{array}{l}\text { Evidence of demand from students that it would make } \\
\text { accessing the service easier for them. }\end{array}$ & 78.8 & 52 & 9.1 & 6 & 12.1 & 8 & 4.03 & 0.92 \\
\hline Evidence of cost effectiveness. & 74.2 & 49 & 6.1 & 4 & 19.6 & 13 & 4.00 & 0.88 \\
\hline Evidenced efficacy of email or other e-counseling & 77.2 & 51 & 3.0 & 2 & 19.6 & 13 & 4.09 & 0.82 \\
\hline Support from principals & 78.8 & 52 & 9.1 & 6 & 12.1 & 8 & 4.15 & 0.85 \\
\hline
\end{tabular}




\section{Main deterrent factors from offering e-counseling in school}

For section five on 'Main deterrent factors from offering e-counseling in school (see Table 3), at least $83.3 \%$ respondents agreed or strongly agreed all the deterrents which were impact of absence of body language; lack of own technical skill; lack of conviction of effective results; quality of therapeutic relationship; accountability of written communication; lack of specific training in e-counseling; and professional development; concern of risk of clients requiring urgent help; fear of miscommunication due to unfamiliar with students' online language; lack of technical or other resources and lack of time boundaries. The lowest score in this section was on question of 'Issues around confidentiality' which was at $80.3 \%(n=53)$. In short, all respondents agreed quite strongly to each of the deterrent item that would hinder them from practicing e-counseling.

The fear of miscommunication due to unfamiliar with students' online language topped at 90.1\% $(n=60 \%)$. Lack of professional development training and technical resources scored at $89.4 \%(n=59)$ respectively.

This could indicate school counsellors still lack of confidence to carry out their $e$-counseling task and without adequate technical support. It was noteworthy to know that $88 \%(n=58)$ school counsellors were concern on the risk of managing urgent help online and its therapeutic effect.

A statistically significant correlation was shown in this section between type of schools and deterrent at $p=.015$. Strong concerns on these deterrent factors were likely come from $86 \%$ of the secondary schools counsellors in this survey.

\section{Cross sectional analysis}

The correlation between intention to use e-counseling and motivator was statistically significant with $\mathrm{p}<.005$. Relationship between the deterrents factor and intention to use e-counseling indicated at $\mathrm{p}<.045$, which was statistically proven significant. However, there was no indication on level of significance between motivator and factor of deterrents, which reflected that both were independent of each other (see Table 4).

Table 3. Section 5 - Main deterrent factors from offering e-counseling in school

\begin{tabular}{|c|c|c|c|c|c|c|c|c|}
\hline \multirow[b]{2}{*}{ Item } & \multicolumn{2}{|c|}{ SA or A } & \multicolumn{2}{|c|}{$\mathrm{D}$ or SD } & \multicolumn{2}{|c|}{$\mathrm{NE}$} & \multirow[b]{2}{*}{ M } & \multirow[b]{2}{*}{ SD } \\
\hline & $\%$ & $n$ & $\%$ & $n$ & $\%$ & $N$ & & \\
\hline Impact of absence of body language & 86.4 & 57 & 9.1 & 6 & 6.1 & 4 & 4.22 & 0.82 \\
\hline Issues around confidentiality & 80.3 & 53 & 9.1 & 6 & 10.6 & 7 & 4.09 & 0.93 \\
\hline Lack of own technical skills. & 83.3 & 55 & 10.6 & 7 & 6.1 & 4 & 3.98 & 0.98 \\
\hline Lack of conviction of effective results & 84.8 & 56 & 13.6 & 9 & 1.5 & 1 & 3.98 & 0.98 \\
\hline Quality of therapeutic relationship & 87.8 & 58 & 9.1 & 6 & 3.0 & 2 & 4.15 & 0.92 \\
\hline Accountability of written communication & 84.8 & 56 & 9.1 & 6 & 4.5 & 3 & 4.06 & 0.79 \\
\hline $\begin{array}{l}\text { Lack of specific training in e-counseling and professional } \\
\text { development }\end{array}$ & 89.4 & 59 & 3.0 & 2 & 7.6 & 5 & 4.23 & 0.72 \\
\hline Concern of risk of clients requiring urgent help. & 87.9 & 58 & 3.0 & 2 & 9.1 & 6 & 4.29 & 0.70 \\
\hline $\begin{array}{l}\text { Fear of miscommunication due to unfamiliar with students' } \\
\text { online language }\end{array}$ & 90.1 & 60 & 4.5 & 3 & 4.5 & 3 & 4.29 & 0.76 \\
\hline Lack of technical or other resources. & 89.4 & 59 & 4.5 & 3 & 6.1 & 4 & 4.17 & 0.74 \\
\hline Lack of time boundaries & 86.4 & 57 & 6.1 & 4 & 7.6 & 5 & 4.11 & 0.79 \\
\hline
\end{tabular}

Note: $\mathrm{SA}=$ Strongly Agree; $\mathrm{A}=$ Agree; NE=Neither; $\mathrm{D}=$ Disagree; $\mathrm{SD}=$ Strongly Disagree. Percentage may not total 100 due to rounding

Table 4. Pearson Correlation of Three Main Sections of the Perception of School Counsellors Towards e-counseling

\begin{tabular}{|c|c|c|c|c|}
\hline & & $\begin{array}{c}\text { Intention to use } \\
\text { e-counseling }\end{array}$ & Motivators & Deterrents \\
\hline $\begin{array}{c}\text { Section 3: } \\
\text { Intention to use e-counseling }\end{array}$ & $\begin{array}{c}\text { Correlation } \\
\text { Sig }\end{array}$ & 1 & $\begin{array}{c}.343 * * \\
.003 \\
\end{array}$ & $\begin{array}{c}-0.249 * \\
.023 \\
\end{array}$ \\
\hline \multirow{2}{*}{$\begin{array}{l}\text { Section 4: } \\
\text { Motivator }\end{array}$} & Correlation & $.343^{* *}$ & 1 & .157 \\
\hline & Sig. & .003 & & .106 \\
\hline \multirow{2}{*}{$\begin{array}{l}\text { Section 5: } \\
\text { Deterrents }\end{array}$} & Correlation & $-0.249 *$ & .157 & 1 \\
\hline & Sig. & .023 & .106 & \\
\hline
\end{tabular}

Note: $* *$ Corelation is significant at the 0.01 level (1-tailed). * Correlation is significant at the 0.05 level (1-tailed) 
It was interesting to note that female counsellors reflected level of statistical significance between motivators to provide e-counseling and intention to use e-counseling at $p=.0004$. A statistically significant relationship registered for $30-39$ years old at $p=.047$ between intention to use e-counseling and motivators for school counsellors to work therapeutically online with students.

Another statistically significant was also showed between motivator and factor of deterrents at $p=.001$ for 30 -39 years old group. School counsellors with $10-15$ years of school counselling experiences also indicated a high level of statistical significance between intention to use e-counseling and motivators at $p=.019$. This group was also had a statistical significance of $p=.013$ between factors of deterrents and motivator.

\section{Discussion}

The results of this study showed an insight on the perceptions of school counsellors towards the use of e-counseling. This study revealed that the intention to use e-counseling was predominantly affected by the competency in technical skill and e-counseling skill training. It is not surprising that more than half of respondent acknowledged their lack of confidence in technical competence in providing e-counseling as evidenced in other discussions (Glasheen et al., 2013; Steele et al., 2014). Timely and regular training in technology would definitely help to enhance their confidence level to use e-counseling (Sabella, Poynton \& Isaacs, 2010; Steele et al., 2014).

In addition to that, school counsellors were more comfortable with availability of e-counseling equipment and chatroom to render their e-counseling services. Schools' additional infrastructures primarily came from decision by school principals (Glasheen, et.al, 2017). Therefore, principals played a vital role in providing not only on e-counseling facilities but also sending school counsellors to appropriate professional development and technical trainings to empower them in their overall skill (Othman, 2000; Anthony, 2015; Steele et al., 2014; Hennigan \& Goss, 2016; O' Dea et al., 2017). Past studies indicated that adequate professional development was the key to overcome the barrier in applying e-counseling in schools (Glasheen et al., 2013; Finn \& Barak, 2010; Hennigan and Goss, 2016).

Unlike some studies reported that school counsellors were skeptical about the effectiveness of e-counseling (Sabella et al., 2010; Glasheen et al., 2013 \& 2015), more than half of the school counsellors in this study expressed their belief in the effective of $e$-counseling. The results were in line with some studies in Malaysia that school counsellors acknowledged the effectiveness of e-counseling (Zamani et al., 2010; Salleh et al, 2015)
Majority of them experienced the efficacy of emails or other method of e-counseling besides face-to-face counselling. As discussed in past studies, effectiveness was benchmarked against students' responses that were more honest and authentic due to anonymity and 'safe' environment, accelerated speed of disclosure thus allowing crux of the issues revealed faster (Glasheen et al., 2009; Baker and Ray, 2011; Salleh et al., 2015).

Almost all $(90 \%)$ viewed that they needed technical equipment to enhance their $e$-counseling role. This is likely due to the fact that not all counselling and guidance units in Malaysia schools are appropriately equipped with required Internet technology (Othman, 2000). This inclination implied that support from ministry level or school-specific such as principals is essential. Almost $80 \%$ of the school counsellors in this survey viewed principals as a motivator to offer e-counseling service as school principals could determine such practice for implementation and financial support (Glasheen et al., 2017; Kok \& Low, 2017). Online communication technologies with latest hardware and software are deemed important to support $e$-counseling.

Despite various views on the effectiveness of e-counseling, it actually opens more opportunities for school counsellors to reach students in their IT-savvy culture (Zamani et al., 2010; Kok, 2016; Teh \& Acosta, 2014). Demand on e-counseling from students reflected that students were keener to seek counselling help online than face-to-face counselling due to stigma issues (Fang et al., 2017; Zainudin \& Yusop, 2018). Studies had reported that many young people with issues would not approach for help if online help were not made available to them (Dowling \& Rickwood, 2014; Glasheen \& Campbell, 2009; Glasheen et al., 2015). Therefore, e-counseling provides a platform for anonymity and a safe environment that allows more students to be connected, reached and counselled (Bambling et al., 2008; Harrad \& Banks, 2016; Hanley et al., 2017).

While motivating factors could encourage higher use of $e$-counseling, there were critical factors that would deter school counsellors to render their e-counseling services. It was interesting to find that at least $80 \%(n=53)$ of school counsellors in this survey agreed or strongly agreed with the concerns on absence of body language, confidentiality, lack of technical skill, lack of conviction of effective results, quality of the therapeutic relationship, accountability on written communication, lack of trainings, risk of clients requiring urgent help, fear of miscommunication due to unfamiliar with online language, lack of technical resources and lack of time boundaries.

Top key deterrent that hinder school counsellors from offering e-counseling was the fear of miscommunication due to the gap with students' online language (90\%). Familiarity of online language posed challenges for school counsellors. School counsellors had to constantly keep themselves updated with the online communication culture to reduce unnecessary miscommunication (Harrad \& Bank, 
2014; Hennigan \& Goss, 2016; Fang et al., 2017).

Lack of technical resources and professional development were another critical factor in offering e-counseling. $91 \%$ of respondents agreed or strongly agreed to these two factors. This matched with the top preferred motivating factor. The availability of $e$-counseling facilities would encourage implementation of e-counseling. Conversely, the unavailability would discourage the use of $e$-counseling. Studies had highlighted that the need to connect with students, bridging the communication gap through their online culture (Sabella et al., 2010; Steele et al., 2014; Demers \& Sullivan, 2014).

Another concern was the ability to response to students' urgent help online. $88 \%$ showed viewed that as a challenge to manage urgent or emergency cases. School counsellors needed training to enhance their confidence in accurate assessment without body language, provide clear communication on alternative contacts for emergency cases after service hour (Steele et al., 2014).

School counsellors (86\%) were worried about lack of time boundaries as they were a misconception that more time would be taken up in addition to their already heavy workload. This contributed to their reluctance and unwillingness to add this modality into their practice (Low et al, 2014; O' Dea et al., 2017; Glasheen et al., 2017). Online process can be controlled just like face-to-face counselling hours in school based on the needs (2017). School counsellors can allocate their time accordingly without additional work hours.

While writing is seen as therapeutic and can accelerate self-disclosure (Barak et al, 2008, Walker in Lau et al., 2013), $85 \%$ found less confidence in the accountability of their writing. Some school counselors viewed that as a burden to them since the chat responses in writing require careful thinking (Fang et al, 2017). It is notable that frustration may happen for school counsellors who are not good in writing (Haberstroh, 2010).

There was two contradictory area emerged in this survey. The results on intention of school counsellor to use $e$-counseling indicated a belief in the effectiveness of e-counseling for therapeutic relationship and yet $85 \%$ supported the lack of conviction of effective results in $e$-counseling at the same time. Doubt over the effectiveness would never create a healthy counselling alliance or therapeutic relationship. Thus, these two areas should be further examined.

In term of demographic profile of this survey, they was not much significant findings except female counsellors were more motivated to use $e$-counseling and those aged 30 - 39 years who made up $58 \%$ of total respondents, had a positive perception towards e-counseling in terms of intention to use coupled with motivating factors.

The result of this study showed that intention to use e-counselling was highly influenced by motivators and deterrents factors that would eventually determine their intention, It is obviously that school counsellors require constant training and support to fully equip them to manage their $e$-counseling effectively and efficiently.

The authors suggested that professional development, technical skill trainings are extremely important to empower school counsellors and enhance their competency in order to confidently put e-counseling into practice. These trainings will help school counsellors to address their concerns, improve their skills and provide best practice for reference. It is also important to ensure schools are equipped with appropriate and latest online technology equipment to maximize their practice.

\section{Limitation}

This study is limited on the inferences in only one district in Selangor. Sample size is relatively small with a gender skewed. Therefore, possibility of biases could potentially affect the results. As such, the results of this study cannot be generalized.

Future research should have a larger sample size with wider coverage for a better representation to the population.

\section{Conclusions}

Instill competency and confidence in their e-counseling and technical skill are the key to encourage and propagate the use of $e$-counseling among school counsellors. These trainings, at continuous manner, will not only enhance the confidence of school counsellor in e-counseling but also address their concerns from time to time, giving school counsellors the needed comfortable level and support to implement this modality effectively so as to reach more students who are in need in their Internet world.

\section{REFERENCES}

[1] Anthony, K. (2015). Traning therapists to work effectively online and offline within digital culture. British Journal of Guidance and Counselling, 43(1), 36-42.

[2] Campbell, M. \& Colmar, S. (2014). Current Status and Future Trends of School Counseling in Australia. Journal of Asia Pacific Counseling, 4 (2), 181-197.

[3] Baker, D. K., \& Ray, M. (2011): Online counseling: The good, the bad, and the possibilities, Counselling Psychology Quarterly, 24(4), 341-346.

[4] Bambling, M., King, R., Reid, W., \& Wegner, K. (2008). Online counselling: The experience of counsellors providing synchronous single-session counselling to young people, Counselling and Psychotherapy Research: Linking research with practice, $8(2), 110-116$.

[5] Finn, J., \& Barak, A. (2010). A descriptive study of 
e-counsellor attitudes, ethics, and practice. Counseling \& Psychotherapy Research, 10(4), 268-277.

[6] Beidoğlu, M., Dinçyürek, S., \& Akıntuğ, Y. (2015). The opinions of school counselors on the use of information and communication technologies in school counseling practices: North Cyprus schools. Computers in Human Behavior, 52, 466-471.

[7] Callahan, A., \& Inckle, K. (2012). Cybertherapy or psychobabble? A mixed methods study of online emotional support. British Journal of Guidance \& Counselling, 40 (3), 261-278.

[8] Cipolletta, S., \& Mocellin, D. (2017). Online counseling: An exploratory survey of Italian psychologists' attitudes towards new ways of interaction. Psychotherapy Research, 28(6), 909-924.

[9] Cook, J. E., \& Doyle, C. (2002). Working Alliance in Online Therapy as Compared to Face to Face Therapy: Preliminary Results. Online Psychology \& Behavior, 5(2), 95-105.

[10] Demers, J. A., \& Sullivan, A. L. (2016). Confronting the ubiquity of electronic communication and social media: ethical and legal considerations for psychoeducational practice. Psychology in the Schools, 53(5), 517-532.

[11] Fang, L., Tarshis, S., McInroy, L., \& Mishna, F. (2017). Undergraduate student experiences with text based online counselling. British Journal of Social Work, 1-17.

[12] Field, A. (2013). Discovering statistics using IBM SPSS Statistics (4th ed.). London, England: Sage Publications.

[13] Gatti, M. F., Brivio, E., \& Calciano, S. (2016). "Hello! I know you help people here, right?" A qualitative study of young people's acted motivations in text based counseling. Children and Youth Services Review, 71, 27-35.

[14] Glasheen, J. K., \& Campbell, A. M. (2009). The use of online counselling within an Australian secondary school setting: a practitioner's viewpoint. Counselling Psychology Review, 24(2), 42-51.

[15] Glasheen, K., Campbell, M., \& Shochet, I. (2013). Opportunities and challenges: School guidance counsellor's perception of counselling students online. Australia Journal of Guidance and Counselling, 23(2), 222- 235.

[16] Glasheen, K., Campbell, M., \& Shochet, I. (2015). School Counsellors' and Students' Attitudes to Online Counselling: A Qualitative Study. Journal of Relationships Research, 6(2), $1-10$.

[17] Glasheen, K., McMahon, M., Campbell, M., Rickwood, D., \& Shochet, I. (2017). Implementing Online Counselling in Australian Secondary Schools: What Principals Think. International Journal for the Advancement of Counselling, 40(1), 14-25.

[18] Glasheen, J. K., Shochet, I., \& Campbell, A. M. (2016). Online counselling in secondary schools: would students seek help by this medium? British Journal of Guidance \& Counselling, 44(1), 108-122,

[19] Harrad R., Banks N. (2016). Counselling in Online Environments. In: Attrill A., Fullwood C. (eds) Applied Online Psychology. London: Palgrave Macmillan.

[20] Haberstroh, S. (2010). School counselor's use of informal language online: Student perception of expertness, trustworthiness and attractiveness. Online Psychology, Behavior, and Social Networking, 13(4), 455 - 459.

[21] Hennigan, J., \& Goss, P. S. (2016). UK secondary school therapist's online communication with their clients and future intentions. Counseling and Psychotherapy Research, 16(3), 149-160

[22] King, R., Bambling, M., Reid, W., \& Thomas, I. (2006). Telephone and online counselling for young people: A naturalistic comparison of session outcome, session impact and therapeutic alliance. Counselling and Psychotherapy Research, 6(3), 175-181.

[23] Kit, P, L., Teo, C. T., Tan, M., Park, Y. (2017). Singapore counsellors' online counselling experiences with children: An exploratory qualitative survey. Journal of Asia Pacific Counseling, 7(2), 141-168.

[24] Kok, J. K. (2016). e-counselling Modality: Following the changing learning of young people in higher education institutions of Malaysia. In Amzat, I.H. \& Yusuf, B. Fast forwarding higher education institutions for global challenges. Springer Science+Business Media Singapore.

[25] Kok, J. K., \& Low, S. K. (2017). Proposing a collaborative approach for school counseling. International Journal of School \& Educational Psychology, 5(4), 281-289.

[26] Low, S. K., Kok, J. K., \& Lee, M. N. (2013). A holistic approach to school based counselling and guidance services in Malaysia. School Psychology International, 34(2), 190-201.

[27] Malaysia Communication Multimedia Commission (2017). Internet users survey 2017: Statistical brief number twenty one. Putrajaya. Retrieved fromhttps://www.mcmc.gov.my/ skmmgovmy/media/General/pdf/MCMCInternetUsersSurv ey2017.pdf

[28] Malaysia Education Statistics (Quick Facts 2018). Ministry of Education, Malaysia.https://www.moe.gov.my/menume $\mathrm{dia} /$ media-cetak/penerbitan/terbitan/buku-informasi/1587-q uick-facts-2018-malaysia-educational-statistics-1/file

[29] Mesch, G. S. (2012). Technology and youth. New Directions for Youth Development. 135, 97-105.

[30] Mishna, F., Bogo, M., \& Sawyer, J-L. (2013). Cyber Counseling: Illuminating Benefits and Challenges. Clinical Social Work Journal, 43(2), 169-178.

[31] National Health and Morbidity Survey 'NHMS'. (2017), Institute of Public Health. Ministry of Health Malaysia. Retrieved from http://iku.moh.gov.my/images/IKU/Docum ent/REPORT/NHMS2017/NHMS2017Infographic.pdf

[32] O'Dea, B., King, C., Subotic-Kerry, M., O'Moore, K., \& Christensen, H. (2017). School Counselors' Perspectives of a Web Based Stepped Care Mental Health Service for Schools: Cross Sectional Online Survey. The Journal of Medical Internet Research (JMIR) Mental Health, 4(4), e55.

[33] Paterson, S. M., Laajala, T., \& Lehtelä, P.L. (2019). Counsellor students' conceptions of online counselling in Scotland and Finland. British Journal of Guidance \& Counselling, 47(3), 292-303.

[34] Richards, D., \& Viganó, N. (2013). Online Counseling: A Narrative and Critical Review of the Literature. Journal of 
Clinical Psychology, 69(9), 994-1011.

[35] Sabella, R. A., Poynton, T. A., \& Isaacs, M. L. (2010). School counselors perceived importance of counseling technology competencies. Computers in Human Behavior, 26(4), 609-617.

[36] Salleh, A., Hamzah, R., Nordin, N., Ghavifekr, S., \& Joorabchi, T. N. (2015). Online counseling using email: a qualitative study. Asia Pacific Education Review, 16(4), 549-563.

[37] Steele, T. M., Jacokes, D. E., \& Stone, C. B. (2014). An examination of ther of online technology in school counseling. Professional School Counseling, 18(1), 125-135.

[38] Suler, J. (2010). Interpersonal guidelines for texting. International Journal of Applied Psychoanalytic Studies, 7(4), 358-361.

[39] Teh, A, L., Acosta, C. A., Hechanova, M. R.M., Garabiles, R. M., \& Alianan Jr, S. A. (2014). Attitudes of Psychology Graduate Students toward Face-to-Face and Online Counseling. Philippine Journal of Psychology, 47(2), 65-97.

[40] Wilczenski, F. L., \& Coomey, S. M. (2006). Cyber Communication: Finding its Place in School Practice, Education, and Professional Development. Professional School Counselor, 9(4), 327-331.

[41] Zainudin, Z, N., \& Yusof, M. Y. (2018). Client's Satisfaction in Face-To-Face Counselling and Online Counseling Approaches: A Comparison. International Journal of Academic Research in Business and Social Sciences, 8(3), 677-684.

[42] Zamani, Z. A., Nasir, R., \& Yusooff, F. (2010). Perceptions towards online counseling among counselors in Malaysia. Procedia Social and Behavioral Sciences, 5, 585-589. 